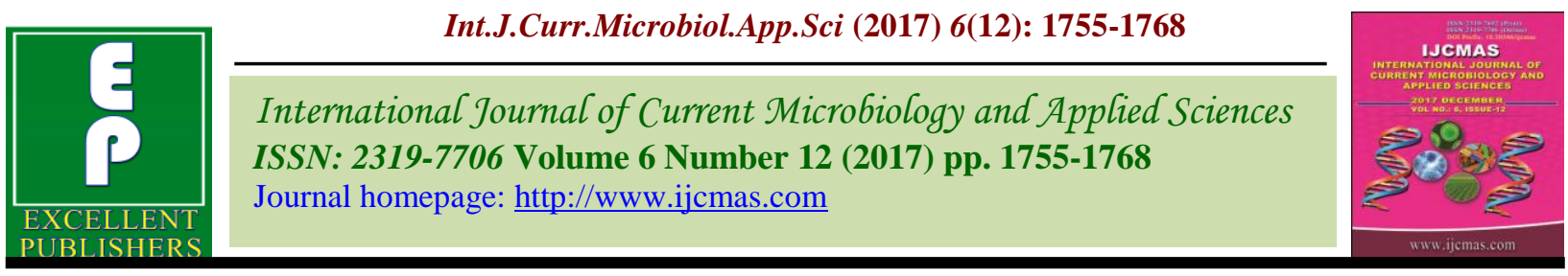

Original Research Article

https://doi.org/10.20546/ijcmas.2017.612.199

\title{
Effect of Prebiotic Inulin on the Fermentation and Growth Kinetics Pattern of Probiotic Yoghurt Bacteria
}

\author{
Jagrani Minj and Shilpa Vij ${ }^{*}$ \\ Dairy Microbiology Division, ICAR-National Dairy Research Institute, \\ Deemed University Karnal, Haryana - 132001, India \\ *Corresponding author
}

A B S T R A C T

\begin{abstract}
Keywords
Inulin, Yoghurt culture, Probiotic, Growth kinetics, Prebiotic.

Article Info

Accepted:

15 October 2017

Available Online:

10 December 2017 w/w) to assess the growth kinetics pattern of Streptococcus thermophilus (ST 144) and Lactobacillus delbrueckii ssp. bulgaricus (LB 144) in the growth medium M-17 and MRS as well as in cow milk medium. The growth rate was found significantly $(P<0.05)$ higher in 3\% inulin supplemented M-17 and MRS $0.21 \pm 0.00$ and $0.24 \pm 0.00$ respectively. In cow milk medium growth rate was significantly $(P<0.05)$ higher and similar for both the culture in 3\% inulin supplemented medium. Generation time (in h) for ST 144 and LB 144 was also found significant $(P<0.05)$ in $3 \%$ inulin supplemented medium $1.28 \pm 0.01$ and $1.43 \pm 0.02$ respectively. Changes in $\mathrm{pH}(\Delta \mathrm{pH})$ and acidity ( $\Delta$ acidity) were also studied for individual culture in cow milk medium. Viability was also highly significant $(P<0.05)$ at day 7 in $3 \%$ inulin supplemented milk medium. This research showed that the addition of inulin as a prebiotic in broth and cow milk medium stimulated the growth and viability of NCDC yoghurt cultures which can be further used to incorporate in fermented milk product yoghurt for increasing its biofunctional properties.
\end{abstract}

In this study, the sugar was replaced using different concentration of inulin $(1,2$ and $3 \%$

\section{Introduction}

The most common inulin is a fructan type which is generally used in the food products as a dietary component to add the prebiotic effect. It is mainly extracted from the chicory root. Addition of biopolymer prebiotic like inulin stimulates the growth of bacteria by acting as carbon source. This property leads to addition of inulin like prebiotic to develop synbiotic food products. The demands of synbiotic products are very popular due to its combined health effects of probiotic and prebiotics (Holzapfel and Schillinger, 2002). Among available prebiotics, inulin and fructooligosaccharides are most famous prebiotics (Maukonen et al., 2008; Roy, 2005).
Addition of prebiotics in foods increases the functional properties of that food, so that it is considered as functional ingredients. The established amounts of fibres to be add in any food products are range from 3-6\% (w/w) in solid food products and in liquid type of foods it is ranged from $1.5-3 \%(\mathrm{w} / \mathrm{w})$ is mostly preferred (Anvisa, 2002). Prebiotic RaftilosesP95 at $1.5 \%(\mathrm{w} / \mathrm{v})$ improved the viability of combined probiotic organisms $L$. acidophilus, L. casei, L. rhamnosus and Bifidobacterium spp. during four week of storage at 4 degree Celsius (Capela et al., 2006). The benefits of prebiotics like fructooligosaccharides, inulin, oligofructose and 
galactosyllactose have been shown in powder infant formula also (Perez-Conesa et al., 2005). The low concentration of inulin supplementation significantly improved the viability and growth of $L$. casei and $L$. acidophilus in yoghurt during storage (Donkor et al., 2007). Oliveira et al., (2011) reported that prebiotic inulin supplemented fermented skim milk and cocktail by $L$. rhamnosus, L. acidophilus, L. bulgaricus and Bifidobacterium lactis, binary co-cultures with $S$. thermophilus has helped in the shorten of generation time. Yoghurt culture is a combination of two bacterial cultures $S$. thermophilus and Lactobacillus delbrueckii ssp. bulgaricus. Application of yoghurt starter cultures can be useful in the development of functional fermented dairy products. Functional properties of fermented milk product can be enhanced by addition of healthy probiotic bacteria like lactobacilli and bifidobacteria which are already claimed for their number of health benefits like antimicrobial activity against harmful and pathogenic bacteria, protective action against antibiotic associated diarrhoea, food allergy and anti-cancer effects (Cummings et al., 2001). The prebiotics or dietary fibres promotes the growth of probiotic bacteria thus improves their survivability. As per definition of FAO/WHO, (2002), "Probiotics are those microorganisms that when consumed in adequate amounts, confer health benefits on consumer $\left(10^{6}-10^{7} \mathrm{CFU} \mathrm{g}{ }^{-1}\right.$ or $\left.\mathrm{mL}^{-1}\right)$ ". On the other side, prebiotics are defined by Coussement (1996) and Gibson et al., (2000), that "the prebiotics are non-digestible food ingredient that beneficially affects the host by selectively stimulating the growth and/or activity of one or a limited number of bacteria in the colon". Miremadi and Shah (2012) have been reported many health benefits of inulin incorporated synbiotic foods in gastrointestinal health and balance of good bacteria in the gut and improvement of their survivability.
Incorporation of prebiotics like oligosaccharides, dextran and inulin also improves the textural properties. Dietary fibers are very useful for techno-functional properties like improvement of body and texture of products, appearance, whey syneresis, water holding capacity, $\mathrm{pH}$, viscosity and acceptability (Dello Staffolo et al., 2004; Silva, 1996; Franck, 2000). The effect of short chain length prebiotic inulin at $1.5 \mathrm{~g} / 100 \mathrm{~g}$ was studied on fat free plain yoghurt using $S$. thermophilus, L. bulgaricus and $L$. casei starter cultures and it was noted that viscosity was not affected by inulin but low syneresis was observed and $\mathrm{pH}$ was also significantly lowered than control. Flavour, body and texture were found comparable better in short chain length inulin supplemented yoghurt (Aryanaa and McGrew, 2007).

Lactic acid bacteria especially yoghurt bacteria are widely consumed worldwide. So, to incorporation of prebiotic fibres in the yoghurt like product can be quite useful for yoghurt bacteria as well as health perspective. Although the effect of prebiotic inulin with lactobacilli was studied in general but combination of inulin with cow milk and yoghurt bacteria, their growth kinetics, fermentation pattern, effect of prebiotic inulin during storage conditions and survivability of yoghurt bacteria are less studied. Therefore, this project was taken to study the effect of prebiotic inulin on the growth kinetics pattern of yoghurt culture in cow milk for further biofunctional product development.

\section{Materials and Methods}

\section{Bacterial cultures}

Mixed yoghurt culture NCDC 144 was procured from National Collection of Dairy Cultures (NCDC) Karnal, India. This mixed culture was separated individually by 
streaking method i.e. Streptococcus thermophilus 144 (ST 144) and Lactobacillus delbrueckii ssp. bulgaricus 144 (LB 144) and activated in respective growth medium M-17 and De Mann Rogosa Sharpe (MRS) agar. The strains were maintained in litmus milk for short term storage and at $-80{ }^{\circ} \mathrm{C}$ in $30 \%$ glycerol for long term storage and initially grown on MRS and M-17 agar plates at $37^{\circ} \mathrm{C}$ and $42{ }^{\circ} \mathrm{C}$ for $48 \mathrm{~h}$ respectively.

\section{Materials and chemicals}

Cow milk was obtained from model dairy plant NDRI, Karnal and inulin was procured from beneo-orafti Mumbai. DeMann Rogosa Sharpe medium (MRS) and M-17 and other media components were purchased from $\mathrm{Hi}$ media India, Mumbai.

\section{Inoculums preparation}

The inoculum was prepared by sub-culturing twice before growth rate study in M-17 and MRS medium but on the other side in skim milk medium it was prepared in $30 \mathrm{~mL}$ of autoclaved skim milk (10 g / $100 \mathrm{~g}$ of total solids) by addition of overnight grown active culture. Sub-culturing was done twice before preparation of mother inoculum in the skim milk. Each culture was individually used to prepare inoculum by following the same procedure. The bacterial count in this inoculum was ranged from 6.5 to $7.1 \mathrm{log}$ $\mathrm{CFU} / \mathrm{mL}$.

\section{Growth of yoghurt cultures in inulin supplemented M-17 and MRS medium}

NCDC yoghurt cultures were individually grown in M-17 (Tryptone 5.0 g, Peptone 5.0 $\mathrm{g}$, Yeast extract $2.5 \mathrm{~g}$, Beef extract $5.0 \mathrm{~g}$, Sodium- $\beta$-glycerophosphate $19.0 \mathrm{~g}$, Ascorbic acid $0.5 \mathrm{~g}$, Magnesium sulphate $0.25 \mathrm{~g}$, Distilled water $1000 \mathrm{~mL}$ ) and MRS (Peptone $10.0 \mathrm{~g}$, Beef extract $10.0 \mathrm{~g}$, Yeast extract 5.0 $\mathrm{g}$, di-potassium hydrogen phosphate $2.0 \mathrm{~g}$,
Sodium acetate $5.0 \mathrm{~g}$, Ammonium citrate 2.0 $\mathrm{g}$, Magnesium sulphate $0.1 \mathrm{~g}$, Manganese sulphate $0.05 \mathrm{~g}$, Tween $801.0 \mathrm{~g}$, Distilled water $1000 \mathrm{~mL}$ ) medium by supplementation of different concentration of inulin i.e. 1, 2 and $3 \%$ to check the growth rate pattern. Inoculated with respective culture and incubation was done at $42{ }^{\circ} \mathrm{C}$ and $37{ }^{\circ} \mathrm{C}$ for ST 144 and LB 144 respectively. Then kinetic parameters were studied for the growth rate using formula given below in the kinetic parameters section.

\section{Standardization of milk}

Fresh cow milk was taken and standardized for fat and solid not fat (SNF) (3\% and 11$12 \%$ ). Four different lot of cow milk was supplemented with different concentration of inulin $(1 \%, 2 \%$ and $3 \%)$ and without inulin (control). Then milk was subjected to batch pasteurization process. After immediate cooling in ice bath, the milk was distributed in the $250 \mathrm{~mL}$ sterilized flask aseptically and stored at $4{ }^{\circ} \mathrm{C}$ for $24 \mathrm{~h}$ before use.

\section{Growth of yoghurt cultures in cow milk in the presence of inulin}

The sterilized milk samples supplemented with $1 \%, 2 \%$ and $3 \%$ inulin were inoculated individually with ST 144 and LB 144 at the rate of $1 \%$ and incubated at $42{ }^{\circ} \mathrm{C}$ up to $\mathrm{pH}$ 4.5. At this point the fermentation process was stopped and $\mathrm{pH}$ was measured and acidification rate was evaluated along with the run. Since the yoghurt preparation generally takes $4-6 \mathrm{~h}$, the samples were analysed after six $h$ of growth. This was performed in triplicate.

\section{Effect of inulin on growth of yoghurt cultures in milk at refrigeration temperature $\left(4^{\circ} \mathrm{C}\right)$}

All the milk samples fermented for six $h$ were also stored at refrigeration temperature at $4{ }^{\circ} \mathrm{C}$ 
for studying the effect of inulin on survivability of yoghurt culture at low temperature. The samples were analysed for the viable cell count, acidity and $\mathrm{pH}$ during storage of fermented milk for 7 days.

\section{Analysis for $\mathrm{pH}$ and acidity}

The post acidification of fermented milk was analyzed after $1^{\text {st }}$ and $7^{\text {th }}$ day of fermentation, stored at $4{ }^{\circ} \mathrm{C}$, by $\mathrm{pH}$ and acidity determination. The acidity was evaluated using $0.1 \mathrm{~N} \mathrm{NaOH}$ solutions according to the method No. 907.124 (AOAC, 1995), and expressed as percentage lactic acid (LA) in the fermented milk samples.

\section{Viable counts of yoghurt cultures}

Bacterial counts were carried out after day 1 and day 7 of each triplicate samples. The serial dilutions were prepared and viable counts were taken by applying the pour plate technique. Viable counts were represented as mean values. ST 144 and LB 144 were individually counted in M-17 at $42{ }^{\circ} \mathrm{C} / 48 \mathrm{~h}$ and MRS at $37{ }^{\circ} \mathrm{C} / 48 \mathrm{~h}$ respectively (IDF, 2003).

\section{Kinetic parameters}

The kinetic growth rate and acidification were studied by fermentation of cow milk with ST 144 and LB 144 individually. This was also studied in M-17 and MRS medium to determine the growth rate and generation time. During the fermentation process monitoring of acidification was carried out in incubator by maintaining incubation time and temperature for $42{ }^{\circ} \mathrm{C}$ and $6 \mathrm{~h}$ respectively. When the fermentation process completed $\mathrm{i}$. e. $\mathrm{pH}$ reached at 4.5 - 4.6 then fermentation was stopped by aseptically agitating the product with a sterilized stainless steel rod. After that all the samples were analysed for the determination of kinetic parameters.
The kinetic growth rate was studied by taking the viable cell counts on two different time intervals such as $0 \mathrm{~h}$ and $6 \mathrm{~h}$. The growth rate and number of generation time was calculated using the following formula:

Growth rate $\mathrm{K}=\mathrm{n} / \mathrm{t}$ (1)

$\mathrm{n}=\left(\mathrm{N}_{\mathrm{t}}-\mathrm{N}_{\mathrm{o}}\right) / \log _{2} \mathrm{t}(2)$

Where,

$\mathrm{N}_{\mathrm{t}}=\log _{10} \mathrm{CFU} / \mathrm{mL}$ after $6 \mathrm{~h}$

$\mathrm{N}_{\mathrm{o}}=\log _{10} \mathrm{CFU} / \mathrm{mL}$ in $0 \mathrm{~h}$

$\mathrm{n}=$ number of generation

$\mathrm{K}=$ Growth rate constant

$\mathrm{t}=$ time in $\mathrm{h}$

During the incubation period, the rate of change in $\mathrm{pH}(\Delta \mathrm{pH})$ and acidity ( $\Delta$ acidity) was also calculated.

\section{Statistical analysis}

All the experimental data such as growth kinetics, $\mathrm{pH}$, acidity and bacterial counts were presented as mean values. Standard errors were used for mean values for the variation. a, $\mathrm{b}, \mathrm{c}$ and the different letters were used to label values with statistically significant $(P<0.05)$ differences among the values. Software Graphpad PRISM version 5.01 was used to represent the graphical form of data and their analysis.

\section{Results and Discussion}

\section{Kinetic growth rates and generation times}

The kinetics growth rate of the bacteria is given in the Table 1, it has been found that the growth rate pattern of ST 144 and LB 144 in the M-17 and MRS medium respectively along with cow milk medium. The growth rate of ST 144 and LB 144 was significantly $(P<0.05)$ higher $0.21 \pm 0.00$ and $0.24 \pm 0.00$ 
in 3\% of inulin supplemented M-17 medium and MRS medium respectively. Again the growth rate was checked in cow milk medium supplemented with 1, 2 and $3 \%$ of inulin. The growth rate for ST 144 and LB 144 was found to be significant $(P<0.05)$ in $3 \%$ inulin supplemented medium which was similar for both of the cultures $0.23 \pm 0.00$. Similarly, Donkor et al., (2007) and Shah, (2001) also reported that inulin have the prebiotic effect during fermentation. The growth rate was significantly $(P<0.05)$ comparable with control (without inulin and glucose) in M-17 and MRS growth medium i. e. $0.11 \pm 0.00$, $0.20 \pm 0.00,0.21 \pm 0.00$ and $0.21 \pm 0.00$ in control, 1, 2 and $3 \%$ inulin supplemented $\mathrm{M}$ 17 medium respectively and in case of MRS medium it was found $0.12 \pm 0.00,0.22 \pm 0.00$, $0.23 \pm 0.00$ and $0.24 \pm 0.00$ in control, 1,2 and 3\% inulin supplemented MRS medium respectively. Similarly, in the present study, in cow milk medium the growth rate of ST 144 and LB 144 was significantly $(P<0.05)$ higher in $3 \%$ inulin supplemented medium $0.23 \pm 0.00$. The growth rate results of control, $1 \%$ and $2 \%$ inulin supplemented cow medium for ST 144 was $0.21 \pm 0.00,0.21 \pm$ 0.00 and $0.21 \pm 0.00$ respectively. On the other side, LB 144 has shown growth rate $0.21 \pm 0.00,0.21 \pm 0.00$ and $0.22 \pm 0.00$ respectively. These values were significantly $(P<0.05)$ lower than 3\% inulin supplemented medium. This growth rate was observed by taking $\log$ count $\mathrm{CFU} / \mathrm{mL}$ for individual bacteria. From Table 1 it is clear that the highest growth rate have been observed in 3\% of inulin supplemented media. Thus, $3 \%$ of inulin supplementation could be the best choice for incorporation in the preparation of functional food like synbiotic yoghurt or other functional foods. Oliveira et al., (2009) also studied the effect of inulin using $4 \mathrm{~g} / 100 \mathrm{~g}$ and found that the main kinetics parameters like generation time, maximum acidification rate also affected by the inulin supplementation. Similar study on the growth rate was done by Sabo et al., (2015) to check the prebiotic effect of inulin by adding in the MRS medium and reported that prebiotic inulin accelerated the growth of L. plantarum ST16 Pa. The similar pattern of growth rates were observed in this study also. Banerjee et al., (2016) also reported that $L$. casei showed the maximum growth rate at $20 \mathrm{~g} / \mathrm{L}$ of lactose and $0.32 \mathrm{~g} / \mathrm{L}$ of inulin concentration.

Effects of prebiotic inulin on growth rate and doubling time (Td) was also studied by Desai et al., (2007) and found that addition of prebiotic inulin improved the growth rate and decreased the doubling time (ranged from 301 to $751 \mathrm{~min}$ ) and also decreases the fermentation time. In this study, the generation time was also found significantly $(P<0.05)$ higher in 3\% inulin supplemented M-17 medium (1.28 \pm 0.01$)$ and MRS medium (1.43 \pm 0.02). The maximum generation time was found in cow milk medium for ST 144 and LB were $1.36 \pm 0.02$ and $1.37 \pm 0.00$ respectively (Table 2). Oliveira et al., (2011) reported that prebiotic inulin supplemented skim milk fermented and cocktail by L. rhamnosus, L. acidophilus, $L$. bulgaricus and Bifidobacterium lactis, binary co-cultures with $S$. thermophilus significantly affected in reducing the generation time. Langlands et al., (2004) also reported the effect of prebiotic inulin and fructooligosaccharides in human volunteers and concluded that these prebiotics increased the number of bifidobacteria and lactobacilli $\log$ $\mathrm{CFU} / \mathrm{g}$ mucosa and $0.5 \mathrm{~g} \quad \log \mathrm{CFU} / \mathrm{g}$ respectively.

\section{pH and acidity}

The $\mathrm{pH}$ values and change in $\mathrm{pH}$ and acidity of fermented cow milk supplemented with different concentration of inulin are shown in Figure 1 and 2 respectively. Figure 1 and 2 has been shown for the $\mathrm{pH}$ values and acidity at two different time intervals $(0 \mathrm{~h}$ and $6 \mathrm{~h})$ 
and their difference in terms of $\Delta \mathrm{pH}$. The difference in $\mathrm{pH}(\Delta \mathrm{pH})$ was found to be significant $(P<0.05) 2.13 \pm 0.02$ in $3 \%$ inulin supplemented cow milk medium in comparison to $1 \%, 2 \%$ and control $1.96 \pm$ $0.00,1.96 \pm 0.02$ and $1.80 \pm 0.02$ respectively (Fig. 1). The data shown in Figure 2 represent the changes in acidity $\Delta$ acidity at $3 \%$ inulin supplementation which was seen highly significant $(P<0.05) \quad 0.66 \pm 0.01$ in comparison to the $1 \%(0.48 \pm 0.01), 2 \%(0.48$ $\pm 0.01)$, and control $(0.57 \pm 0.02)$ samples. The significant reduction in the $\mathrm{pH}$ has been observed in $3 \%$ inulin concentration. This indicated that the $3 \%$ inulin was the best suited for growth of both the yoghurt bacteria ST 144 and LB 144 for the completing of fermentation as well as for the survivability of both the yoghurt bacteria till a longer time. Similar reports given by Bruno et al., (2002) for skim milk containing $B$. longum Bb-2 supplemented with inulin after 4 week of storage and stated that there was not any significant changes have been observed in the $\mathrm{pH}$ when compared to the control sample. Inulin addition in milk products positively affected the $\mathrm{pH}$ and acidity. Inulin addition in fermented milk decreased the rate of $\mathrm{pH}$ (Hardi and Slacanac, 2000). Apart from effect in $\mathrm{pH}$, inulin also affects the flavour and texture (Seydin et al., 2005) and sensory attributes (Ibrahim et al., 2004). Thus, many techno functional benefits have been shown by the prebiotic inulin which could be a great choice for the development of dairy based functional fermented products.

Table.1 Kinetic growth rates of ST 144 and LB 144 in respective growth medium and in cow milk medium with different concentration of prebiotic inulin supplementation

\begin{tabular}{|c|c|c|c|c|}
\hline \multicolumn{5}{|c|}{$\begin{array}{l}\text { Kinetic data (growth rate) of ST } 144 \text { and LB } 144 \text { in different concentration of inulin supplemented } \\
\text { medium and cow milk medium }\end{array}$} \\
\hline Growth medium & $\begin{array}{l}\text { Without Inulin } \\
\text { and Glucose }\end{array}$ & $\begin{array}{c}1 \% \text { Inulin } \\
\text { supplementation }\end{array}$ & $\begin{array}{c}\text { 2\% Inulin } \\
\text { supplementation }\end{array}$ & $\begin{array}{c}\text { 3\% Inulin } \\
\text { supplementation }\end{array}$ \\
\hline M-17 (ST 144) & $0.11 \pm 0.00^{\mathrm{a}}$ & $0.20 \pm 0.00^{\mathrm{b}}$ & $0.21 \pm 0.00^{\mathrm{c}}$ & $0.21 \pm 0.00^{\mathrm{d}}$ \\
\hline MRS (LB 144) & $0.12 \pm 0.00^{\mathrm{a}}$ & $0.22 \pm 0.00^{\mathrm{b}}$ & $0.23 \pm 0.00^{\mathrm{c}}$ & $0.24 \pm 0.00^{\mathrm{d}}$ \\
\hline Growth medium & Without Inulin & $\begin{array}{c}1 \% \text { Inulin } \\
\text { supplementation }\end{array}$ & $\begin{array}{c}\text { 2\% Inulin } \\
\text { supplementation }\end{array}$ & $\begin{array}{c}\text { 3\% Inulin } \\
\text { supplementation }\end{array}$ \\
\hline Cow Milk (ST 144) & $0.21 \pm 0.00^{\mathrm{a}}$ & $0.21 \pm 0.00^{\mathrm{a}}$ & $0.21 \pm 0.00^{\mathrm{a}}$ & $0.23 \pm 0.00^{b}$ \\
\hline Cow Milk (LB 144) & $0.21 \pm 0.00^{\mathrm{a}}$ & $0.21 \pm 0.00^{\mathrm{a}}$ & $0.22 \pm 0.00^{\mathrm{b}}$ & $0.23 \pm 0.00^{\mathrm{c}}$ \\
\hline
\end{tabular}

Table.2 Generation time of ST 144 and LB 144 in respective growth medium and in cow milk medium with different concentration of prebiotic inulin supplementation

\begin{tabular}{|c|c|c|c|c|}
\hline \multicolumn{5}{|c|}{$\begin{array}{l}\text { Kinetic data (generation time in hr) of ST } 144 \text { and LB } 144 \text { in different concentration of inulin } \\
\text { supplemented medium and cow milk medium }\end{array}$} \\
\hline Growth medium & $\begin{array}{l}\text { Without Inulin } \\
\text { and Glucose }\end{array}$ & $\begin{array}{c}1 \% \text { Inulin } \\
\text { supplementation }\end{array}$ & $\begin{array}{c}2 \% \text { Inulin } \\
\text { supplementation }\end{array}$ & $\begin{array}{c}\text { 3\% Inulin } \\
\text { supplementation }\end{array}$ \\
\hline M-17 (ST 144) & $0.68 \pm 0.02^{\mathrm{a}}$ & $1.21 \pm 0.01^{\mathrm{b}}$ & $1.26 \pm 0.02^{\mathrm{c}}$ & $1.28 \pm 0.01^{\mathrm{d}}$ \\
\hline MRS (LB 144) & $0.70 \pm 0.01^{\mathrm{a}}$ & $1.29 \pm 0.01^{\mathrm{b}}$ & $1.38 \pm 0.01^{\mathrm{c}}$ & $1.43 \pm 0.02^{\mathrm{d}}$ \\
\hline Growth medium & Without Inulin & $\begin{array}{c}1 \% \text { Inulin } \\
\text { supplementation }\end{array}$ & $\begin{array}{c}\text { 2\% Inulin } \\
\text { supplementation }\end{array}$ & $\begin{array}{c}\text { 3\% Inulin } \\
\text { supplementation }\end{array}$ \\
\hline Cow Milk (ST 144) & $1.23 \pm 0.00^{\mathrm{a}}$ & $1.24 \pm 0.01^{\mathrm{a}}$ & $1.29 \pm 0.00^{b}$ & $1.36 \pm 0.02^{\mathrm{c}}$ \\
\hline Cow Milk (LB 144) & $1.27 \pm 0.01^{\mathrm{a}}$ & $1.28 \pm 0.01^{\mathrm{a}}$ & $1.31 \pm 0.01^{\mathrm{b}}$ & $1.37 \pm 0.00^{\mathrm{c}}$ \\
\hline
\end{tabular}


Fig.1 Changes in $\mathrm{pH}$ at two different time interval and their difference

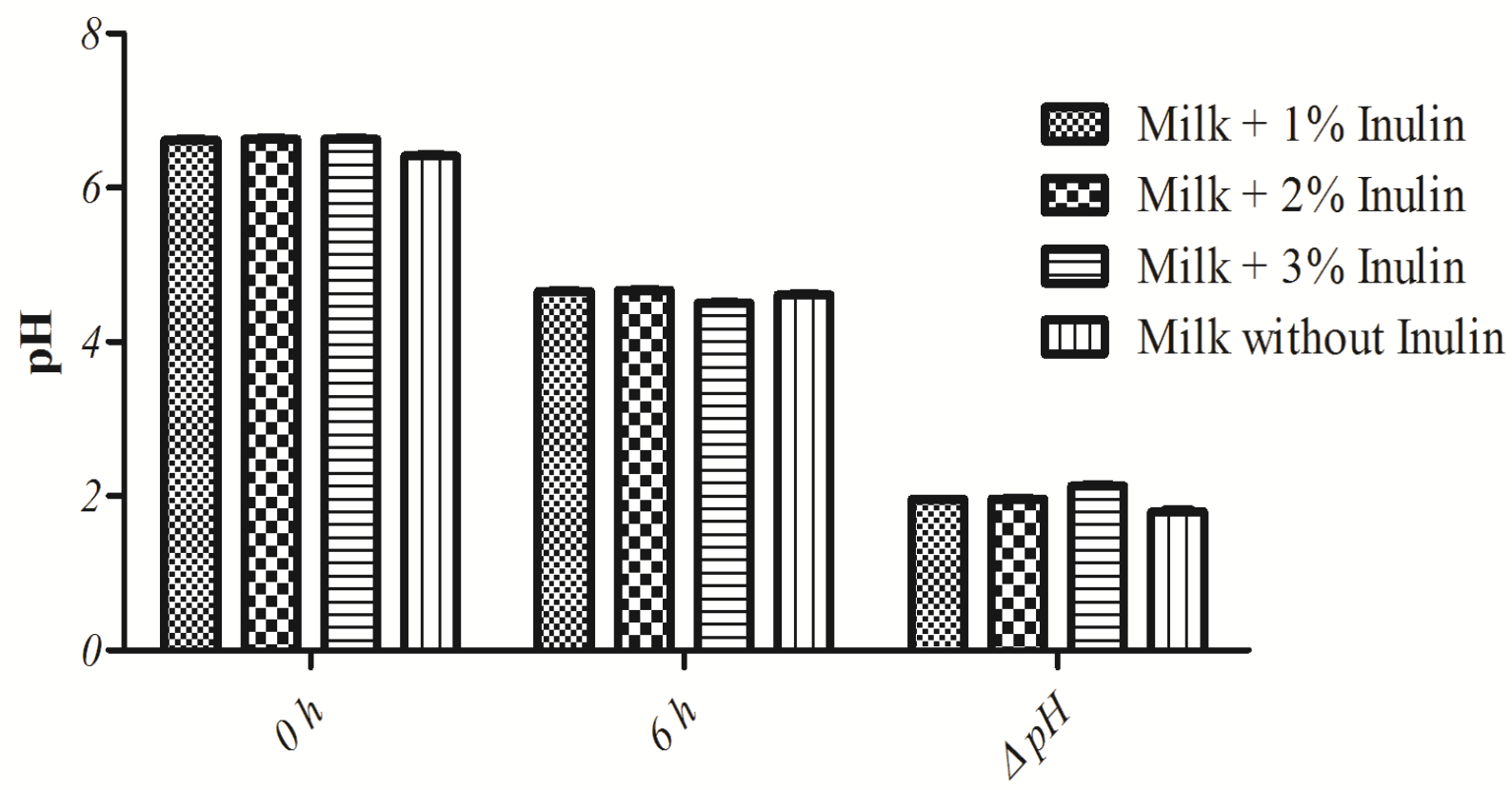

Times in $\mathbf{h}$

Fig.2 Changes in acidity at two different time interval and their difference

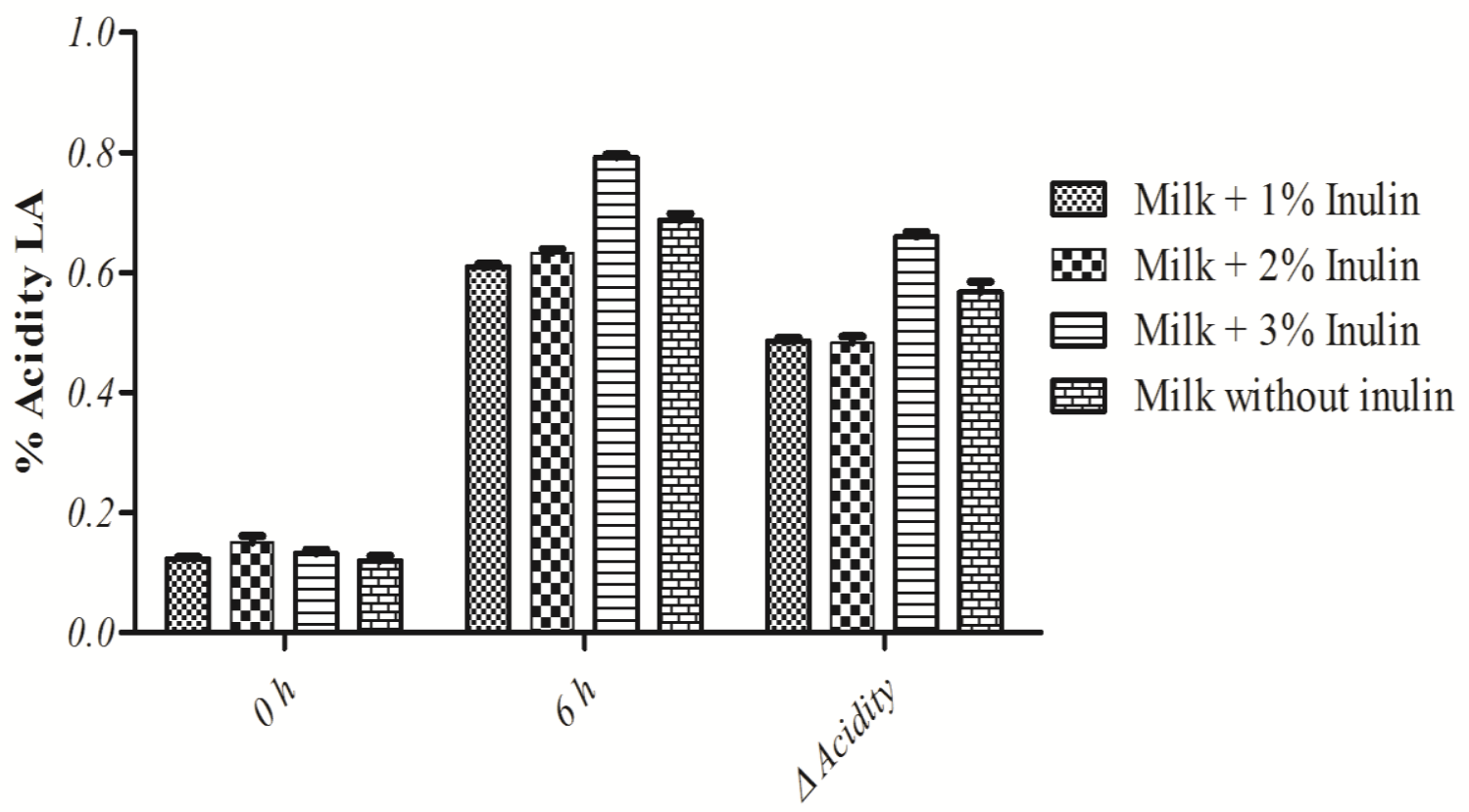

Time interval and their difference in $\mathrm{h}$ 
Fig.3 Changes in $\mathrm{pH}$ at two different time intervals (Storage days)

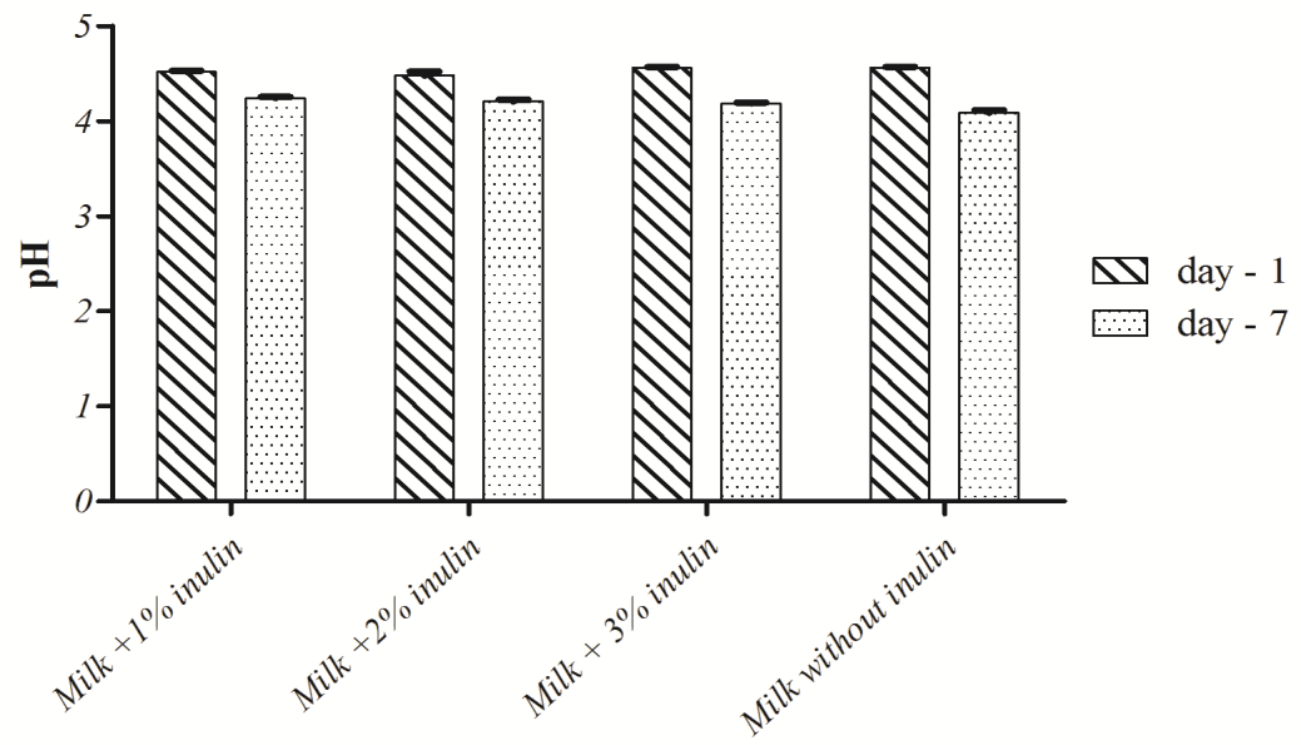

Treatments

Fig.4 Changes in acidity at two different time intervals (Storage days)

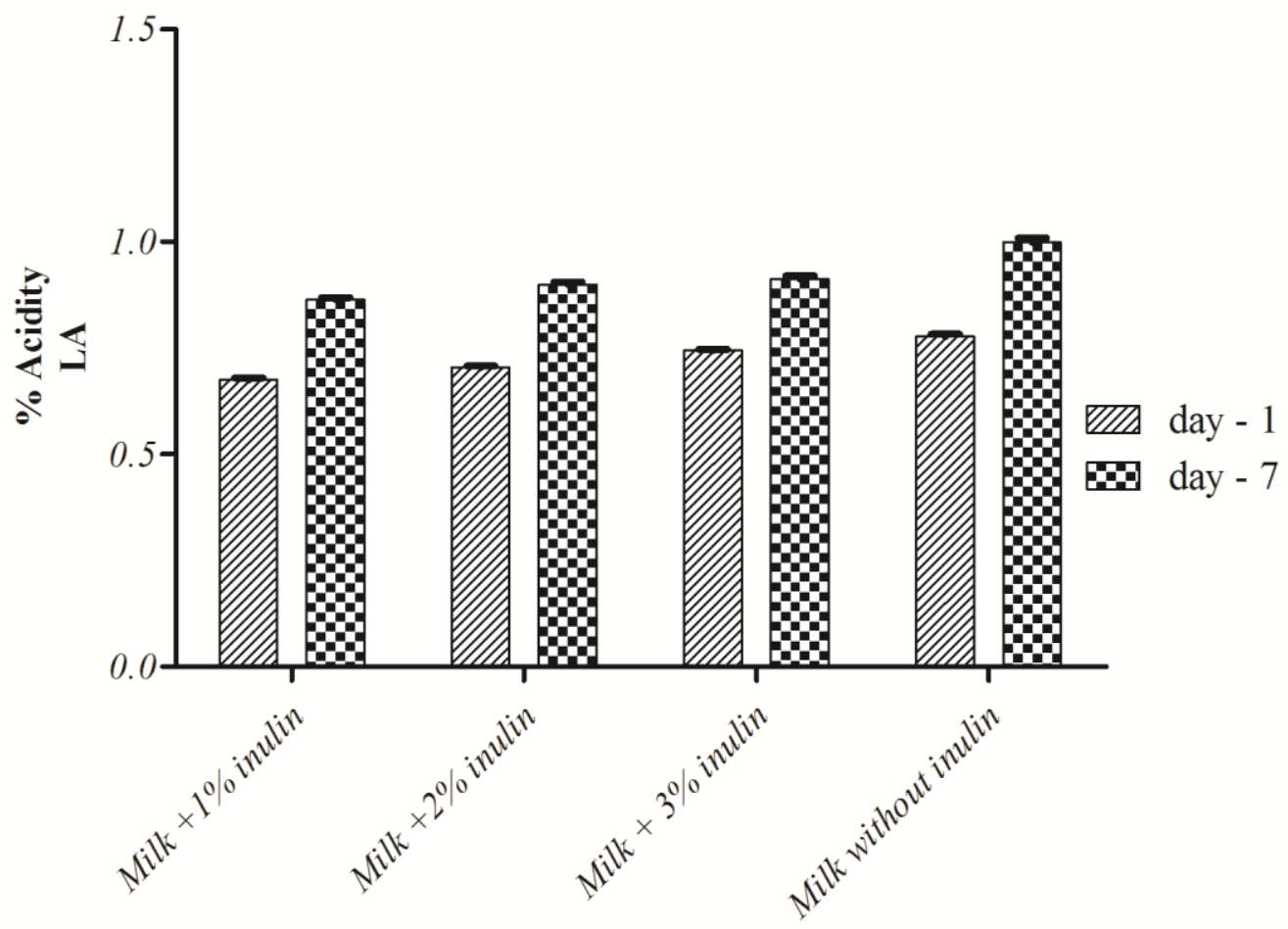

Treatments 
Fig.5 Viability of yoghurt bacteria during storage at day 1

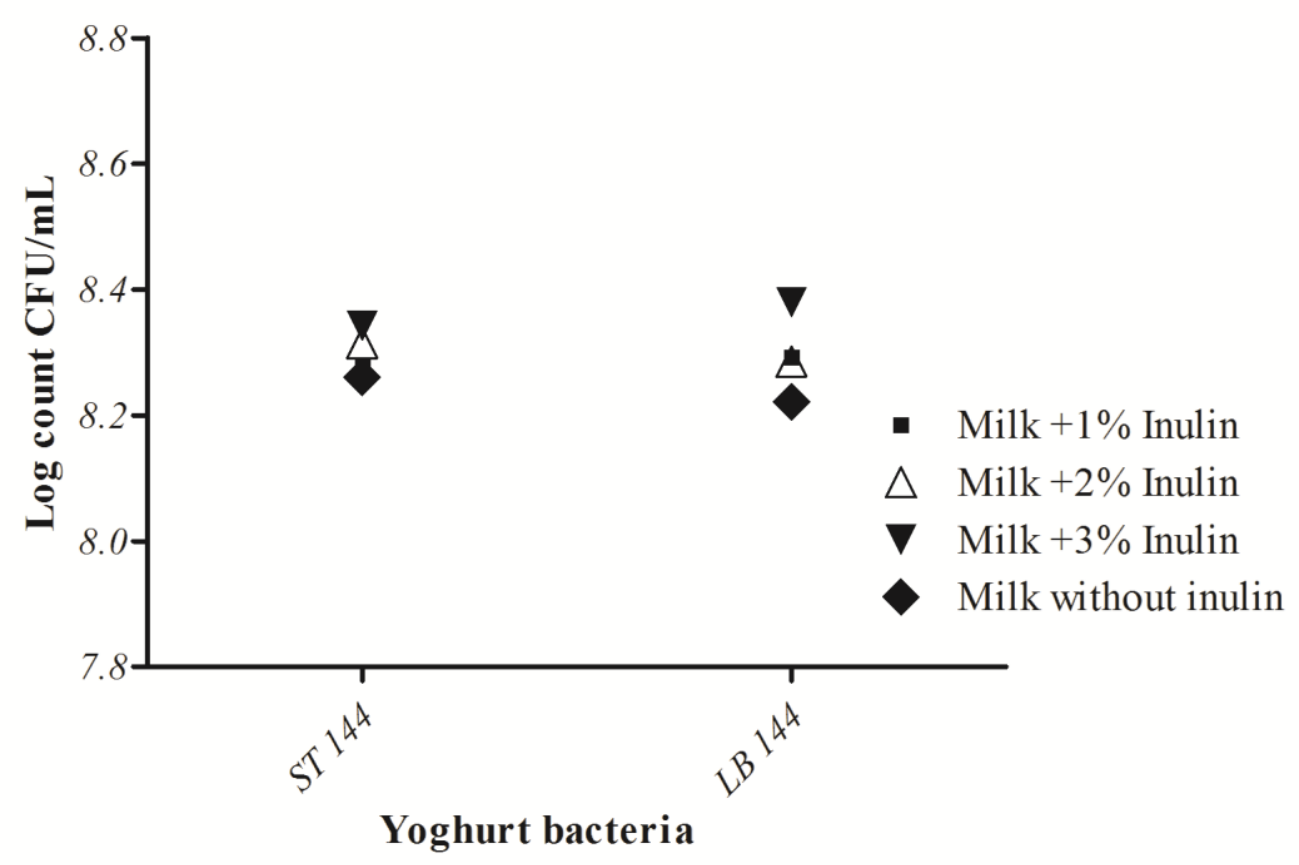

Fig.6 Viability of yoghurt bacteria during storage at day 7

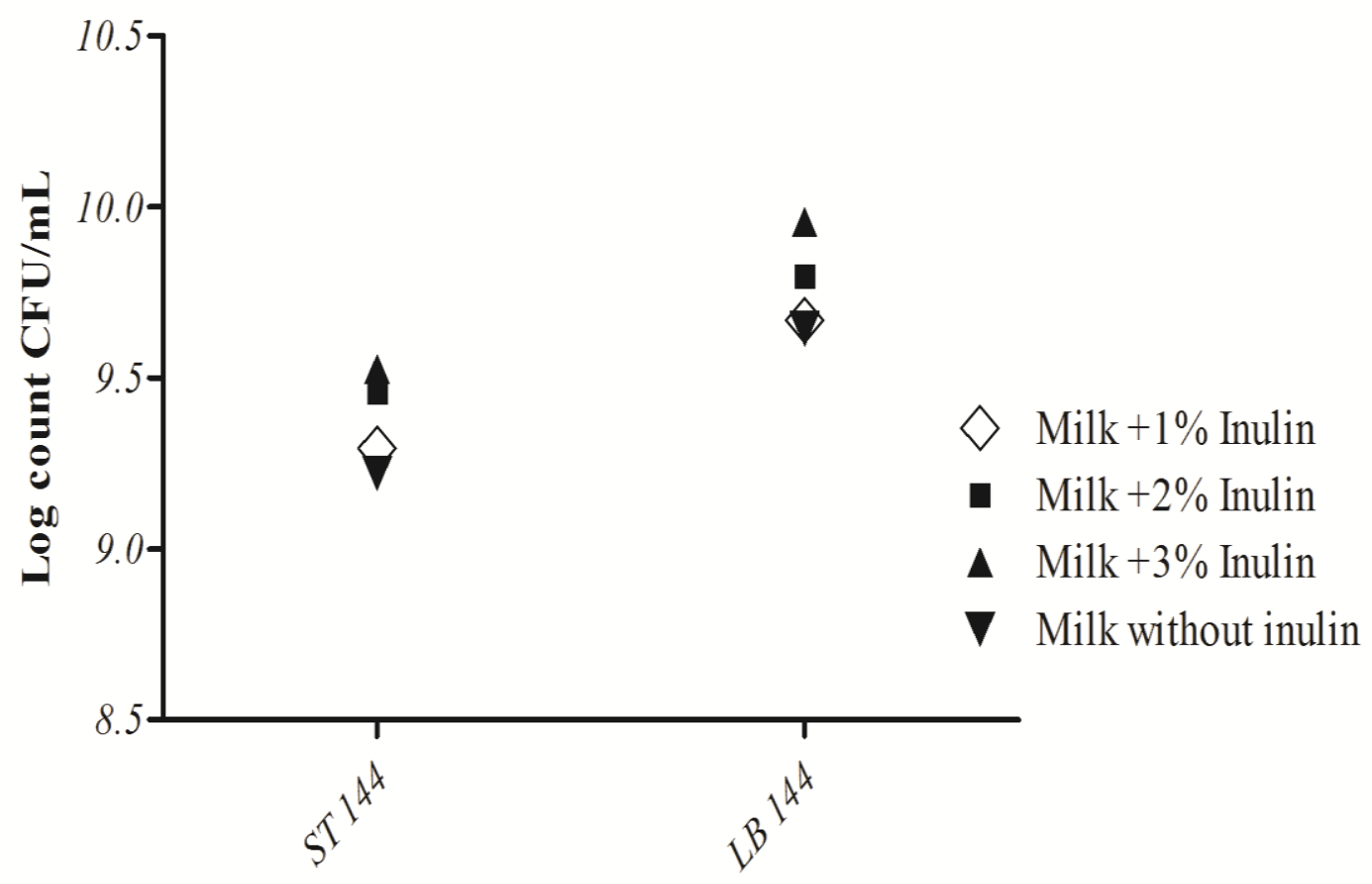

Yoghurt bacteria 
Effect on pH and acidity at low temperature during storage

The $\mathrm{pH}$ and the acidity were also studied on day 1 and day 7 at different concentration of inulin supplemented fermented cow milk medium during the storage at refrigeration temperature $4{ }^{\circ} \mathrm{C}$. There was no significant changes have been observed in day $1 \mathrm{pH}$ in different concentration of inulin supplemented medium but it was found significant $(P<0.05)$ in the changes in $\mathrm{pH}$ at day 7 (Fig. 3). Similarly changes in acidity were also studied on day 1 and day 7 . Again it was noted that 3\% inulin supplemented fermented cow milk having significant $(P<$ 0.05 ) change in acidity $0.74 \pm 0.01$ on day 1 and $0.91 \pm 0.01$ on day 7 (Fig. 4).

Desai et al., (2003) reported that 5\% w/v inulin supplemented skim milk along with Lactobacilli ATCC 15820 shown $\mathrm{pH} 4.10$ during storage at $4^{\circ} \mathrm{C}$ for 4 weeks. Similar types of results have been observed in this study also. The $\mathrm{pH}$ was noted $4.52 \pm 0.02$ on day 1 and it was noted $4.24 \pm 0.01$ in the $1 \%$ inulin supplemented fermented cow milk.

The day $1 \mathrm{pH}$ in $2 \%$ inulin supplemented cow milk medium was noted $4.48 \pm 0.04$ and it was decreased significantly on day 7 i. e. $4.21 \pm 0.02$. In case of $3 \%$ inulin supplemented cow milk the $\mathrm{pH}$ was noted $4.56 \pm 0.01$ and $4.19 \pm 0.01$ on day 1 and day 7 respectively. Whereas the result of control sample cow milk without inulin has the $\mathrm{pH}$ value was $4.56 \pm 0.01$ and $4.09 \pm 0.03$ on day 1 and day 7 respectively. Dello Staffolo et al., (2004) studied and found that reconstituted whole milk powder fortified with inulin have stable $\mathrm{pH}$ and water activity even after storage at $4^{\circ} \mathrm{C}$ for 21 days and rheological parameters like viscosity and textural score were also acceptable. This may be due to the functional characteristics of both the dietary fiber (inulin) and yoghurt.

\section{Bacterial viability count during storage at low temperature}

Bacterial viability was determined by taking $\log$ counts during storage at day 1 and day 7 (Fig. 5 and 6). Fermentation of cow milk was done by co-culturing with ST 144 and LB 144 and individual counts were taken on M-17 and acidified MRS media respectively. Figure 5 indicates the viable count which was taken on day 1 in cow milk supplemented with different concentration of inulin $(1,2$ and $3 \%)$. The viability in terms of $\log$ count CFU/mL of ST 144 and LB 144 was not significantly differ on day 1 but it was significantly changed in the different concentration of inulin supplementation on day 7 . The viability was noted in $1 \%$ inulin supplemented cow milk medium $8.28 \pm 0.03$ for ST 144 and $8.29 \pm 0.02$ for LB 144. The $\log$ count $\mathrm{CFU} / \mathrm{mL}$ was found in $2 \%$ of inulin supplemented cow milk was $8.31 \pm 0.02$ for ST 144 and $8.29 \pm 0.02$ for LB 144. These results were found non-significant in comparison to the control sample i. e. milk without inulin and the results were noted 8.26 \pm 0.03 for ST 144 and $8.22 \pm 0.02$ for LB 144 . The data of $3 \%$ inulin supplemented cow milk medium showed the significant $(P<0.05)$ results $8.34 \pm 0.01$ and $8.38 \pm 0.01$ for ST 144 and LB 144 respectively in comparison to the $1 \%, 2 \%$ and control samples. The viability of Lactobacillus casei Shirota (Lc) and Lactobacillus plantarum Lp33 and Lp17 was studied and reported that prebiotic inulin positively affected the encapsulated probiotic bacteria on their viability during the storage (Peredo et al., 2016).

On the other side the viability of individual culture was taken on day 7 and found that there was a significant $(P<0.05)$ increase in the $\log$ count $\mathrm{CFU} / \mathrm{mL}$ as compared to the day 1. During comparison of $3 \%$ inulin supplemented cow milk medium it was found that one $\log$ increment on day 7 from $8.34 \pm$ 
0.01 to $9.53 \pm 0.03$ in ST 144 and $8.38 \pm 0.01$ to $9.96 \pm 0.01$ in $\mathrm{LB} 144$. These results were quite appreciable to show the effect of prebiotic inulin in the growth and survivability of yoghurt bacteria (Fig. 5 and Fig. 6). The viability of L. casei and La in the $5-15 \mathrm{~g} / \mathrm{L}$ inulin supplemented media was studied by Donkor et al., (2007). The in vivo bifidogenic effect of prebiotic oligofructose was studied by Bielecka et al., (2002) and reported that oligofructose was more effective for synbiotic. The fermentation pattern of dietary fibres or prebiotics depends on type of dietary fibre. This dietary fiber can be soluble or insoluble. The soluble dietary fibres are more effective for bacterial fermentation thus it becomes more beneficial to the gut health (Brownawell et al., 2012; Howlett et al., 2010).

The combination of prebiotic inulin and lactic acid bacteria and probiotic bacteria was mostly studied for their synbiotic effects. Lactobacillus rhamnosus GG and Bifidobacterium lactis $\mathrm{Bb} 12$ containing synbiotic product consisting of inulin have shown significant effects in colon cancer biomarkers and colon cancer patients (Rafter et al., 2007). Skim milk containing inulin and other prebiotics were studied and claimed that $5 \%(\mathrm{w} / \mathrm{v})$ of prebiotic inulin have the greatest viability for lactobacilli during the storage (Desai et al., 2003).

Similar study was done by Etchepare et al., (2016) using a mixture of corn starch and inulin on the survival of microorganisms. The viability of probiotic bacteria affected by prebiotics as it stimulates the growth of probiotic bacteria in the colon where almost not availability of any nutrients. The probiotic bacteria along with prebiotic shows the synergistic effects and this combination are known as symbiotic (Al-Sheraji et al., 2013). The healthy gut microbiota composition balance and increasing the number of bifidobacteria species in the presence of inulin was reported by Meyer and StasseWolthuis, (2009). They also observed that the biomarkers for healthy gut were significantly increased. In another study the viability of Bifidobacteria in the faeces was found increased significantly by the consumption of inulin as a prebiotic powder (Harmsen et al., 2002). The prebiotic inulin promoted the growth of probiotic bacteria when started the depletion of nutrients in the medium. Mumcu et al., (2014) reported that prebiotic substances are good for growth and acidifying performance of L. acidophilus and Bifidobacterium spp. The similar results on growth and acidifying performance were observed in this study also.

This research work indicated that the prebiotic inulin is very useful as a functional ingredient to incorporate in the any fermented milk and milk products like yoghurt to improve its prebiotic effects as well as the ameliorative effect on the growth and survivability of bacteria especially the probiotic yoghurt bacteria. The growth rate was also affected by the concentration of inulin to show the higher bifidogenic effect. The concentration of inulin also affected the $\mathrm{pH}$ and acidity during storage under refrigerated conditions. Thus, we concluded that inulin@3\% is a good choice to use in the synbiotic functional fermented food product development in terms of products $\mathrm{pH}$, acidity as well as the growth kinetic parameters.

\section{Acknowledgements}

The authors acknowledge the National Collection of Dairy Cultures (NCDC), Karnal for providing the yoghurt culture. The authors also acknowledges to the University Grant Commission (UGC) for providing the financial support under the fellowship Rajiv Gandhi National Fellowship. 


\section{References}

Al-Sheraji, S.H., Ismail, A., Manap, M.Y., Mustafa, S., Yusof, R.M., and Hassan, F.A. 2013. Prebiotics as functional foods: A review. Journal of Functional Foods, 5: 1542-1553.

Anvisa. 2002. Aprova o regulamento técnico de substâncias bioativas e probióticos isolados com alegação de propriedades funcional e ou de saúde, Resolução RDC $\mathrm{n}^{\circ}$ 2, January 7, 2002. Agência Nacional de Vigilância Sanitária, Ministério da Saúde, Brasilia, Brazil. Retrieved August 22, 2007, from http://e-legis.bvs.br/leisref/public/ showAct.php?id=1567.

AOAC. 1995. In Official methods of analysis of the association of official analytical chemist international (16th ed., Vols. I and II) Maryland, USA.

Aryanaa, K. J., and McGrew, P. 2007. Quality attributes of yogurt with Lactobacillus casei and various prebiotics. LWT-Food Science and Technology, 40: 18081814.

Banerjee, D., Chowdhury, R., and Bhattacharya, P. 2016. The prebiotic influence of inulin on growth rate and antibiotic sensitivity of Lactobacillus casei. International Journal of Pharmacy and Pharmaceutical Sciences, 8: 181-184.

Bielecka, M., Biedrzycka, E., and Majkowska, A. 2002. Selection of probiotics and prebiotics for synbiotics and confirmation of their in vivo effectiveness. Food Research International, 35: 125-131.

Brownawell, A. M., Lewis, K. D., Caers, W., Gibson, G. R., Kendall, C. W. C., and Lewis, K. D. 2012. Prebiotics and the health benefits of fiber: Current regulatory status, future research, and goals. Journal of Nutrition, 142: 962 974.
Bruno, F. A., Lankaputhra, W. E. V., and Shah, N. P. 2002. Growth, viability and activity of Bifidobacterium spp. in skim milk containing prebiotics. Journal of Food Science, 2740-2744.

Capela, P., Hay, T. K. C., and Shah, N. P. 2006. Effect of cryoprotectants, prebiotics and microencapsulation on survival of probiotic organisms in yoghurt and freeze-dried yoghurt. Food Research International, 39: 203-211.

Coussement, P. 1996. Pre- and synbiotics with inulin and oligofructose: promising developments in functional foods. Food Technology Europe (Dec-Jan), 102104.

Cummings, J. H., Macfarlane, G. T., and Englyst, H. N. 2001. Prebiotic digestion and fermentation. American Journal of Clinical Nutrition, 73: 415S-20S.

Da Silva Sabo, S., Converti, A., Todorov, S. D., Dominguez, J. M., and de Souza Oliveira, R. P. 2015. Effect of inulin on growth and bacteriocin production by Lactobacillus plantarum in stationary and shaken cultures. International Journal of Food Science and Technology, 50: 864-870.

De Araujo Etchepare, M., Raddatz, G. C., de Moraes Flores, E. M., Zepka, L. Q., Jacob-Lopes, E., Barin, J. S., Grosso, C. R. F., and de Menezs, C. R. 2016. Effect of resistant starch and chitosan on survival of Lactobacillus acidophilus microencapsulated with sodium alginate. LWT-Food Science and Technology, 65: 511-517.

De Souza Oliveira, R. P., Perego, P., de Oliveira, M. N., and Converti, A. 2011. Effect of inulin as a prebiotic to improve growth and counts of a probiotic cocktail in fermented skim milk. LWT - Food Science and Technology, 44: 520-523.

Dello Staffoloa, M., Bertola, N., Martino, M., and Bevilacqua, Y. A. 2004. Influence 
of dietary fiber addition on sensory and rheological properties of yogurt. International Dairy Journal, 14: 263268.

Desai, A. R., Powell, I. B., and Shah, N. P. 2004. Survival and activity of probiotic lactobacilli in skim milk containing prebiotics. Journal of Food Science, 69: FMS57-FMS60.

Donkor, O. N., Nilmini, S. L. I., Stolic, P., Vasiljevic, T., and Shah, N. P. 2007. Survival and activity of selected probiotic organisms in set- type yoghurt during cold storage. International Dairy Journal, 17: 657-665.

FAO/WHO. 2002. Health and nutritional properties of probiotics in food including powder milk with live lactic acid bacteria. Report of a Joint FAO/WHO Expert Consultation. C_ordoba, Argentina.

Franck, A. M. 2000. Inulin and oligofructose. In: Gibson, G. and Angus, F., (Eds) LFRA ingredient handbook: Prebiotics and probiotics. p. 1-18. Surrey: Leatherhead Publishing.

Gibson, G. R., Ottaway, P. B., and Rastall, R. A. 2000. Prebiotics. Oxford, U.K.: Chandos Publishing Ltd. p 1-20.

Hardi, J., and Slacanac, V. 2000. Examination of coagulation kinetics and rheological properties of fermented milk products: The influence of starter culture, milk fat content and addition of inulin. Mijekarstvo, 50: 217-226.

Harmsen, H. J. M., Raangs, G. C., and Franks, A. H. 2002. The effect of the prebiotic inulin and the probiotic Bifidobacterium longum on the fecal microflora of healthy volunteers measured by FISH and DGGE. Microbial Ecology in Health and Disease, 14: 211-9.

Holzapfel, W. H., and Schillinger, U. 2002. Introduction to pre- and probiotics. Food Research International, 35: 109-
116.

Howlett, J. F., Betteridge, V. A., Champ, M., Craig, S. A., Meheust, A., and Jones, J. M. 2010. The definition of dietary fiberdiscussions at the ninth vahouny fiber symposium: Building scientific agreement. Food and Nutrition Research, 54: 5750.

Ibrahim, G. A., Mehanna, N. S., El-Rab, D. A. G., Abd El-Salam, M. H., Kholif, A. M., Abdou, S. M., and El-Shibiny, S. 2004. Preparation and properties of set fermented milk containing inulin and different probiotics. In $9^{\text {th }}$ Egyptian Conference for Dairy Science and Technology, Cairo, Egypt, October 911, 2004 (pp. 117-132). Cairo, Egypt: Egyptian Society of Dairy Science.

IDF. 2003. Yoghurt/Enumeration of Characteristic Microorganisms, Colony Count Technique at $37^{\circ} \mathrm{C}$, Standard No. 117, International Dairy Federation, Brussels.

Langlands, S. J., Hopkins, M. J., and Coleman, N. 2004. Prebiotic carbohydrates modify the mucosa associated microflora of the human large bowel. Gut, 53: 1610-6.

Maukonen, J., Matto, J., Kajander, K., Mattila-Sandholm, T., and Saarela, M. 2008. Diversity and temporal stability of fecal bacterial populations in elderly subjects consuming galactooligosaccharide probiotic yoghurt. International Dairy Journal, 18: 386395.

Meyer, D., and Stasse-Wolthuis, M. 2009. The bifidogenic effect of inulin and oligofructose and its consequences for gut health. European Journal of Clinical Nutrition, 63: 1277-1289.

Miremadi, F., and Shah, N. P. 2012. Applications of inulin and probiotics in health and nutrition. International Food Research Journal, 19: 1337-1350.

Mumcu, A. S., and Temiz, A. 2014. Effects of 
prebiotics on growth and acidifying activity of probiotic bacteria. Gida, 39: 71-77.

Oliveira, R. P., De, S., Perego, P., Converti, A., and De Oliveira, M. N. 2009. Growth and acidification performance of probiotics in pure culture and coculture with Streptococcus thermophilus: The effect of inulin. LWT-Food Science and Technology, 42: 1015-1021.

Peredo, A. G., Beristain, C. I., Pascual, L. A., Azuara, E., and Jimenez, M. 2016. The effect of prebiotics on the viability of encapsulated probiotic bacteria. $L W T$ Food Science and Technology, 73: 191196.

Perez-Conesa, D., Lopez, G., and Ros, G. 2005. Fermentation capabilities of bifidobacteria using nondigestible oligosaccharides, and their viability as probiotics in commercial powder infant formula. Journal of Food Science, 70: 279-285.
Rafter, J., Bennett, M., Caderni, G., Clune, Y., Hughes, R., Karlsson, P. C., Klinder, A., O'Riordan, M., O'Sullivan, G., Pool-Zobel, B., Rechkemmer, G., Roller, M., Rowland, I., Salvadori, M., Thijs, H., Loo, J. H., Watzl, B., and Collins, J. K. 2007. Dietary synbiotics reduce cancer risk factors in polypectomized and colon cancer patients. American Journal of Clinical Nutrition, 85: 488 -96.

Roy, D. 2005. Review: technological aspects related to the use of bifidobacteria in dairy products. Le Lait, 85: 39-56.

Seydin, Z. B. G., Sarikus, G., and Okur, O. D. 2005. Effect of inulin and dairy-Lo as fat replacers on the quality of set type yogurt. Milchwissenschaft, 60: 51-55.

Shah, N. P. 2001. Functional foods from probiotics and prebiotics. Food Technology, 55: 46-53.

Silva, R. F. 1996. Use of inulin as a natural texture modifier. Cereal Food World, 41: 792-795.

\section{How to cite this article:}

Jagrani Minj and Shilpa Vij. 2017. Effect of Prebiotic Inulin on the Fermentation and Growth Kinetics Pattern of Probiotic Yoghurt Bacteria. Int.J.Curr.Microbiol.App.Sci. 6(12): 17551768. doi: https://doi.org/10.20546/ijcmas.2017.612.199 